\title{
Prostate cancer reporting and staging: needle biopsy and radical prostatectomy specimens
}

\author{
David J Grignon \\ Department of Pathology and Laboratory Medicine, Indiana University School of Medicine, IUH Pathology \\ Laboratory, Indianapolis, IN, USA
}

\begin{abstract}
Prostatic adenocarcinoma remains the most common cancer affecting men. A substantial majority of patients have the diagnosis made on thin needle biopsies, most often in the absence of a palpable abnormality. Treatment choices ranging from surveillance to radical prostatectomy or radiation therapy are largely driven by the pathologic findings in the biopsy specimen. The first part of this review focuses on important morphologic parameters in needle biopsy specimens that are not covered in the accompanying articles. This includes tumor quantification as well as other parameters such a extraprostatic extension, seminal vesicle invasion, perineural invasion, and lymphovascular invasion. For those men who undergo radical prostatectomy, pathologic stage and other parameters are critical in prognostication and in determining the appropriateness of adjuvant therapy. Staging parameters, including extraprostatic extension, seminal vesicle invasion, and lymph node status are discussed here. Surgical margin status is also an important parameter and definitions and reporting of this feature are detailed. Throughout the article the current reporting guidelines published by the College of American Pathologists and the International Collaboration on Cancer Reporting are highlighted.

Modern Pathology (2018) 31, S96-S109; doi:10.1038/modpathol.2017.167
\end{abstract}

The morphologic aspects of prostatic adenocarcinoma have a critical role in the management and prognostication of patients with prostatic adenocarcinoma. Today, most men diagnosed with prostatic adenocarcinoma have the diagnosis made on a needle biopsy, the majority of which are performed for an elevated serum PSA. Management recommendations for these patients are driven by a number of clinical and pathologic factors. In current practice, a significant percentage of patients judged to have low-risk disease are placed on surveillance protocols. Criteria for identification of patients suitable for surveillance are largely based on characterization of the tumor in the prostate needle biopsy specimen. ${ }^{1,2}$ Of note is the increasing interest in identifying patients of intermediate risk that also can be safely placed on surveillance protocols. $^{3}$ For those patients that elect radical prostatectomy as the primary treatment, the pathologic findings in the resection specimen are critical for prognostication and for determining the appropriateness of adjuvant treatment such as radiation therapy or

Correspondence: Dr DJ Grignon, MD, Department of Pathology and Laboratory Medicine, Indiana University School of Medicine, IUH Pathology Laboratory, 300 West Eleventh Street, Indianapolis, IN 46202, USA.

E-mail: dgrignon@iupui.edu

Received 2 August 2017; revised 10 October 2017; accepted 14 October 2017 hormonal therapy., ${ }^{4,5}$ For needle biopsy specimens the data described below are largely based on standard biopsy protocols ranging from the original sextant (6 cores) to more contemporary extended techniques (1214 cores). How these features will relate to the targeted MRI-guided biopsy technique is not well understood.

In this article, the reporting of prostatic adenocarcinoma in needle biopsy and radical prostatectomy specimens is reviewed. The recommendations follow recent guidelines from the College of American Pathologists (Tables 1 and 2) and the International Collaboration on Cancer Reporting. ${ }^{6-9}$ For radical prostatectomy specimens the recommendations from the International Society of Urological Pathology are also referenced. ${ }^{10-14}$ Topics covered in accompanying articles in this journal issue, including histologic type (see Humphrey PA, Zhou M, and Osunkoya A), Gleason grading (see Epstein JI), intraductal carcinoma (see Zhou M), and treatment effect (see Evans A) are not repeated here.

\section{Needle biopsy specimens}

\section{Tumor Quantitation}

The quantification of tumor in needle biopsy specimens is a powerful predictor of pathologic stage at radical prostatectomy and outcome after treatment of 
Table 1 College of American Pathologists Reporting Guidelines: Needle Biopsy (modified from College of American Pathologists Protocol for the Examination of Specimens from patients with Carcinoma of the Prostate Gland) ${ }^{6}$

\section{Histologic type}

Histologic grade

Gleason primary (predominant) pattern

Gleason worst remaining pattern

Grade group

Percentage pattern 4 (for Gleason score $3+4=7$ )

*Percentage Gleason patterns 4 and 5 (for Gleason score $\geq 7$ )

Intraductal carcinoma (document if identified)

\section{Tumor quantitation}

Number cores positive/total number cores and percentage of prostatic tissue involved

Number cores positive/total number cores

and total linear mm carcinoma/total linear mm tissue or

Number cores positive/total number cores and percentage of prostatic tissue involved and total linear mm carcinoma/total linear mm tissue

Periprostatic fat invasion (document if identified)

Seminal vesicle/ejaculatory duct invasion (document if identified)

*Lymphovascular invasion

*Perineural invasion

*Additional pathologic findings

*Data elements not required for accreditation purposes.

essentially any type. It is also a factor in determining patient suitability for management on a surveillance protocol. ${ }^{2}$ Quantification of tumor for surveillance protocols have variably used parameters such as the absolute number of cores involved (two or three), the percentage of cores involved $(<20 \%$ or $<33 \%$ or $<50 \%$ ), and the greatest percentage of any core involvement ( $<50 \%$ of any core; $<30 \%$ or $6 \mathrm{~mm}$ of any core). ${ }^{2}$ There are strong correlations between the absolute number of cores involved and the proportion of cores involved with tumor volume in the prostate gland and with pathologic stage. ${ }^{15-18}$ There is also a strong correlation with outcome in patients treated by radical prostatectomy or radiation therapy. ${ }^{18-20}$

Reporting the number of cores received and the number of cores involved is a required element for prostate needle biopsy specimens. ${ }^{6,8}$ For cases submitted with one core per site in separate containers this is straightforward. For the most part, if the number of cores per container is limited to two (eg, left apex and left lateral apex) this can usually also be accomplished. When more than two cores are placed in a container and/or when the number of cores placed in each container is not specified this becomes problematic and often essentially impossible. In the example in Figure 1 there are numerous fragments of tissue, three of which are involved by cancer. From the specimen, it is impossible to know how many cores were actually placed in the container. If it is known that this represents, for example, three cores, it is impossible to know if the
Table 2 College of American Pathologists Reporting Guidelines: Radical Prostatectomy (modified from College of American Pathologists Protocol for the Examination of Specimens from patients with Carcinoma of the Prostate Gland) ${ }^{6}$

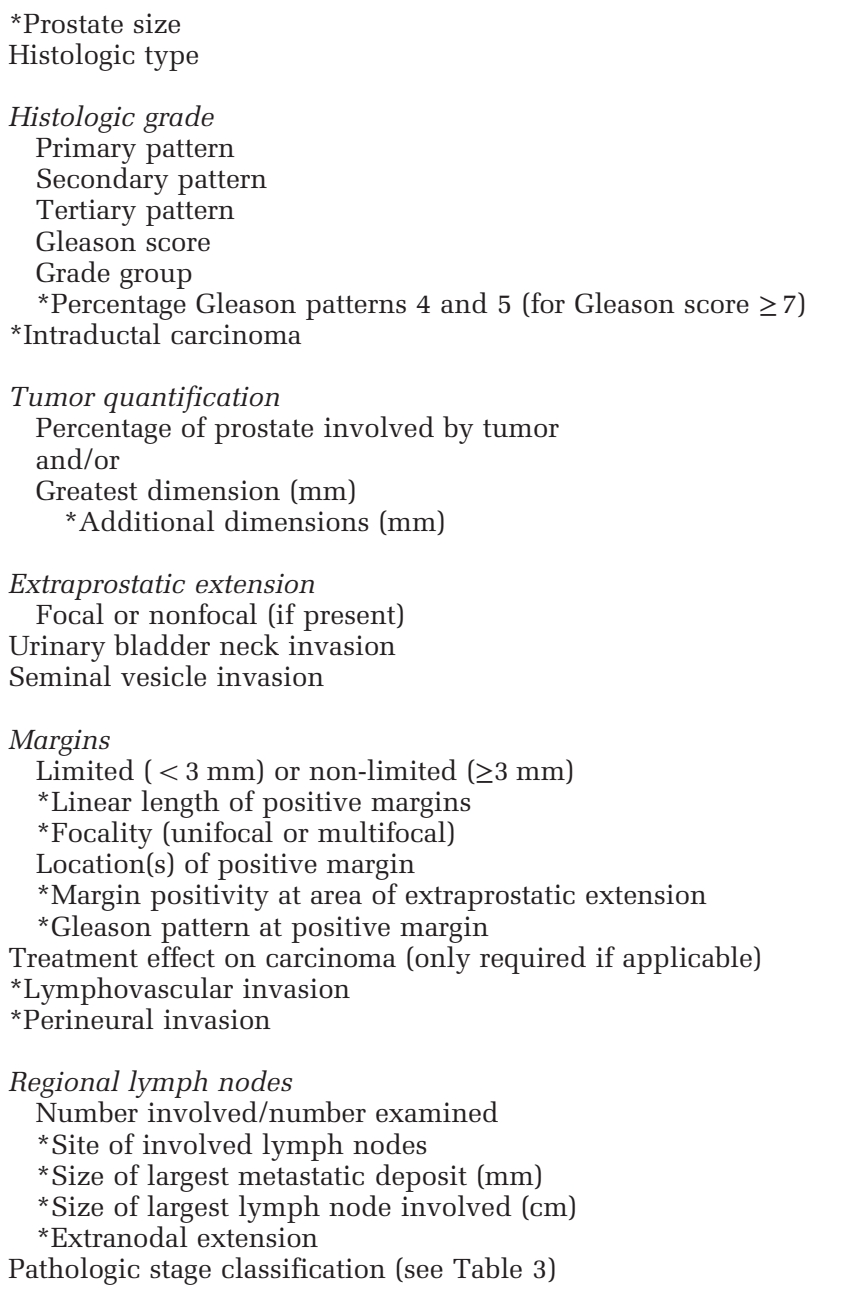

*Data elements not required for accreditation purposes.

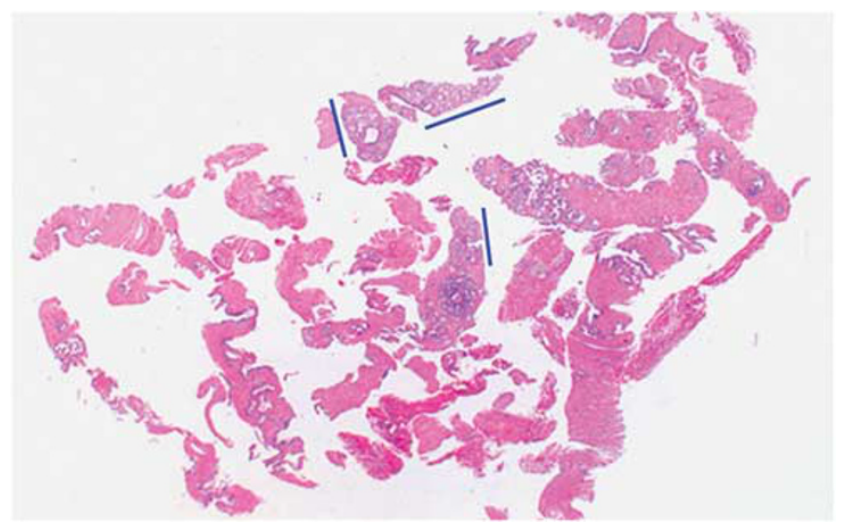

Figure 1 Scan of a glass slide from a needle core biopsy specimen. The needle biopsy cores are extensively fragmented making it impossible to determine the actual number of cores submitted in the container. The blue lines mark the three tissue fragments that contain adenocarcinoma. Determining the number of cores involved by the carcinoma is similarly not possible in this case. 


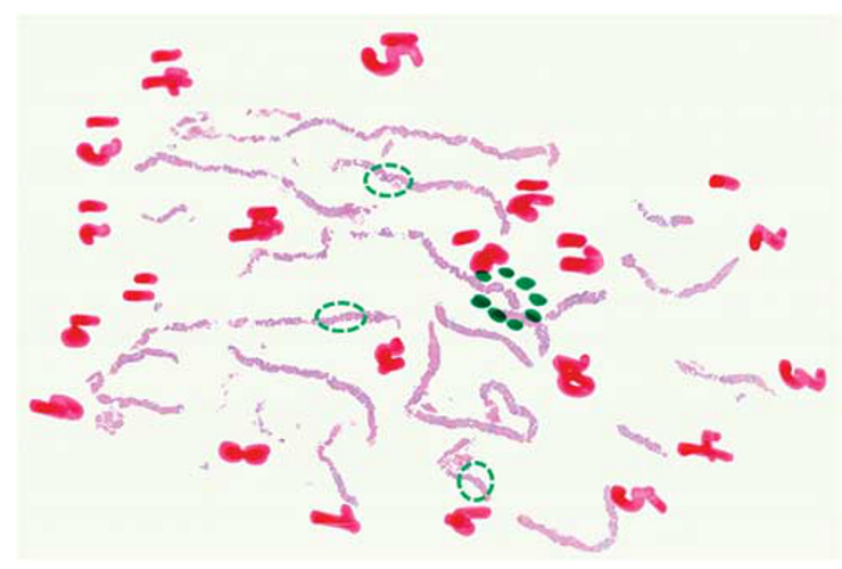

Figure 2 Scan of a glass slide from a needle core biopsy specimen. The pathologist counted the tissue fragments and reported that there were 21 cores present (numbers were on slide when received from referring institution). A more accurate way of reporting this specimen would be that there were 21 tissue fragments; the number of submitted cores is impossible to determine. It was also reported that there were 4 cores positive for cancer (green); the number of cores that had tumor is not known but it would be accurate to indicate that 4 of the tissue fragments contained tumor.

three involved fragments are from one, two, or three of the cores. Given the critical need to provide both the number of cores submitted and the number involved, this type of specimen argues very much for placement of a specified number (one or two) of cores in individually labeled containers. In another example (Figure 2), the pathologist dutifully counted each piece of tissue on the slide (the numbering on the slide is as received in our lab) and each piece with cancer and then in the synoptic report indicated 'number of cores: 21' and 'number of positive cores: 4.' This implies some level of ability to make this determination. The submitting urologist will know how many cores were in the container (undoubtedly not 21) but even with that knowledge would be unable to determine the absolute number involved or the proportion involved. Application of criteria for surveillance is impossible in both of these instances. In our practice, for both of these specimens, for the number of cores submitted we would report "not applicable.' For the number of cores involved we would report three and four tissue fragments involved, respectively.

The quantification of the linear extent of tumor in the cores has been approached using many methods. ${ }^{1}$ These have included the use of both millimeter measurements and estimated surface area (percent involvement). Specifics have included length/percentage in each individual core, length/ percentage for the core with the largest amount of tumor, and an overall length/percentage for the entire case. The observation that reporting guidelines do not designate a specific method to be used reflects data indicating no one method has been proven to be superior to others. ${ }^{6,7}$ Studies have generally found that the greater the amount of tumor by any of these methods, the large the volume of tumor in the gland and the more likely that the tumor is not organ confined at radical prostatectomy. ${ }^{15-18}$ Linear measurements in $\mathrm{mm}$ can be determined by ocular micrometer or by knowing the diameter of the field at various magnifications and using this to estimate length.

A substantial and unresolved issue in determining linear extent is how to account for 'skip' areas where there is benign tissue between foci of adenocarcinoma. This is a controversial area with little data to determine the optimal approach. One study with a small number of patients found that using an 'end-toend' approach that included intervening benign tissue in the tumor measurement better predicted tumor volume in the radical prostatectomy. ${ }^{21}$ Another study tested the importance of the length of the intervening tissue in determining whether to include it or not in the tumor measurement and found that if consistently applied, including or excluding benign tissue did not make a significant difference. ${ }^{18}$ In a study comparing an in-house method (end-to-end approach) with percentages reported on the outside, the in-house approach was superior in predicting pathologic stage but the authors did not perform alternate methods themselves on the selected cases. ${ }^{22}$ Another report compared cases where the needle biopsy specimens had only one or two cores involved with the cores having at least $2 \mathrm{~mm}$ of intervening benign tissue with the corresponding radical prostatectomy specimens. ${ }^{23}$ In this study, $78 \%$ of such cases had a solid tumor nodule while $22 \%$ contained only scattered small foci. The authors did not discuss if the length of the benign tissue predicted the likelihood of solid versus multifocal disease. Figure 3 illustrates an extreme example of this issue. Here the two small foci of adenocarcinoma are located at opposite ends of a needle core biopsy. In this case, the pathologist reported the prostatic adenocarcinoma to involve $90 \%$ of the core using an approach that measures tumor without excluding benign tissue. It has been recommended that in such cases the discontinuous nature of the tumor be specified. ${ }^{22}$ If this were the only positive core in this case, it would make the patient ineligible for surveillance. Because of this unresolved issue, a statement from multiple organizations recommended reporting such biopsies using a method that essentially describes what is on the slide. In this instance, the report might read that the core contains ' 2 discontinuous foci measuring $4 \mathrm{~mm}$ in aggregate, involving $15 \%$ of the core, and spanning $80 \%$ of the core.' Providing this detail on all cases with skip lesions would require considerable time and effort but for those infrequent cases where the reporting could alter management for the patient it may be a reasonable approach to take. ${ }^{8}$ 


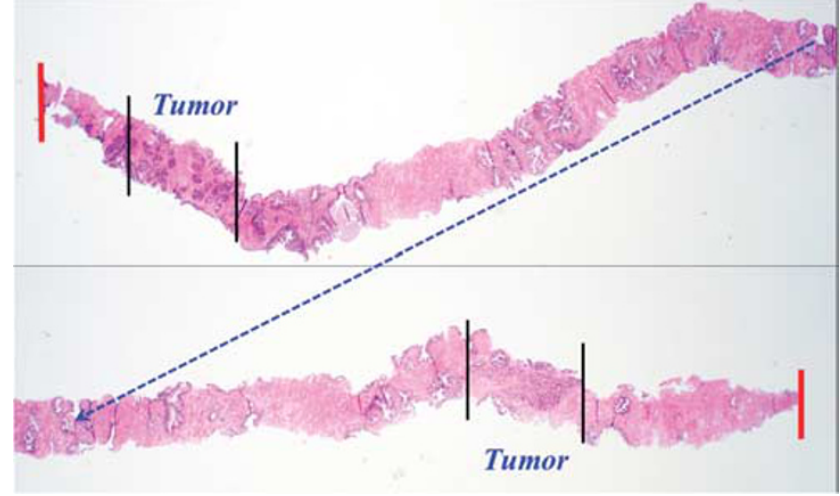

Figure 3 This single needle core biopsy (red marks the opposite ends) contains two discrete foci of tumor (marked with black lines). There is a long segment of uninvolved prostatic tissue intervening. The biopsy was reported as having $90 \%$ involvement by tumor. This can be misleading in an extreme example of skip areas such as this biopsy illustrates. Recent recommendations for cases such as this would quantify the tumor as 'two discontinuous foci measuring $4 \mathrm{~mm}$ in aggregate, involving $15 \%$ of the core, and spanning $80 \%$ of the core. ${ }^{1}$

\section{Periprostatic Fat Invasion (Document if Identified)}

Prostate needle biopsy specimens can contain periprostatic fat and when involved by tumor this is equated with there being extraprostatic extension and a pathological stage of at least pT3a. Ravery et al. ${ }^{24}$ published a report where at the time of the sextant biopsy, cores were directed to include extraprostatic tissue. In $75 \%$ of cases where 'capsular penetration' was diagnosed on the core, extraprostatic extension was confirmed at radical prostatectomy. The current standard biopsy approach that includes lateral cores is similar to that used by Ravery et $a .^{24}$ In a series of 72 needle biopsies with extraprostatic extension, Miller et al. ${ }^{25}$ reported that this finding is usually associated with high-stage and high-grade disease. The diagnosis of extraprostatic extension should be limited to only cases where there is unequivocal fat involvement (Figure 4). It is generally agreed that fat is only rarely present within the prostate parenchyma, ${ }^{26-28}$ although one report identified intraprostatic fat in $4 \%$ of totally embedded whole-mounted radical prostatectomy specimen. ${ }^{29}$ These foci consisted of small collections of 5-20 adipocytes. Intraprostatic adipose tissue has also been described in a needle biopsy specimen. ${ }^{30}$ Nonetheless, practically speaking, unequivocal fat involvement in a needle biopsy specimen remains a surrogate for extraprostatic extension and should be reported when present. ${ }^{6,8}$

\section{Seminal Vesicle/Ejaculatory Duct Invasion (Document if Identified)}

Seminal vesicle invasion (pT3b) is defined by the 'tumor infiltration of the muscular wall of the seminal vesicle.' Because of difficulties with
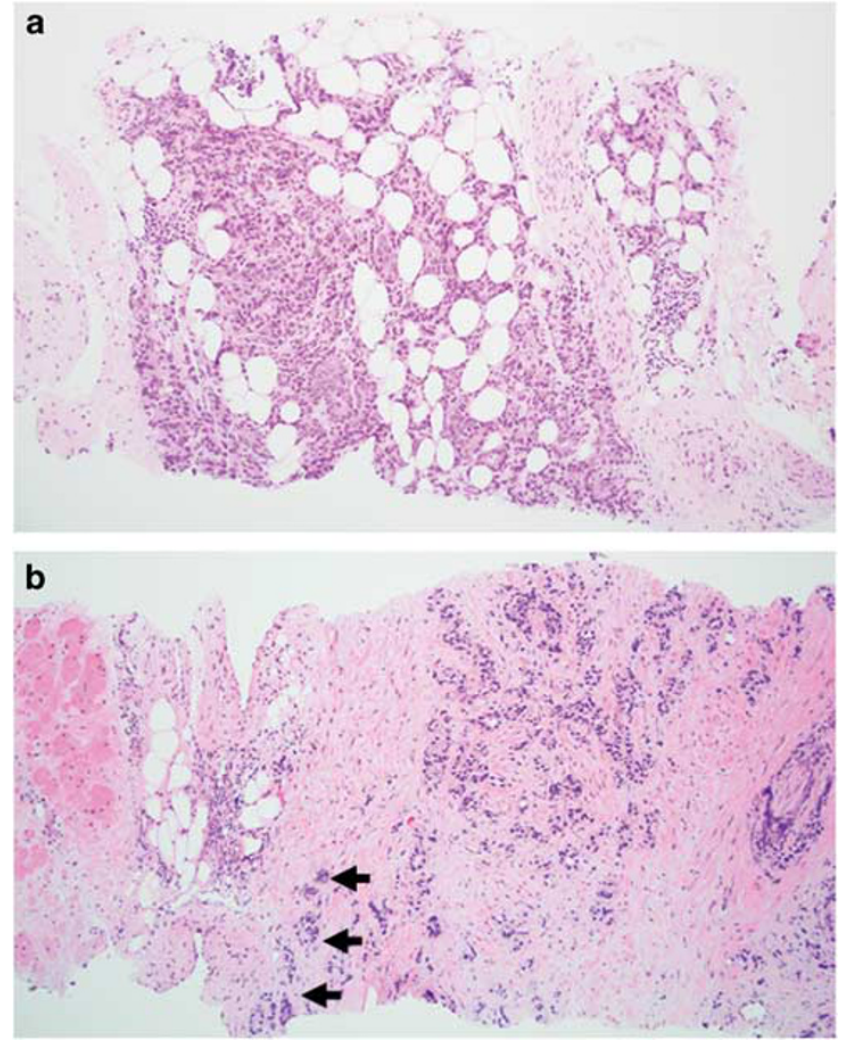

Figure 4 A prostate needle biopsy specimen showing unequivocal involvement of fat (a). When this is present, it should be reported as indicating the presence of extraprostatic extension. The second image (b) shows carcinoma close to fat but not involving it. In cases like this, it is not possible to accurately diagnose extraprostatic extension and so need not be reported.

anatomic definitions for seminal vesicle and ejaculatory duct, it is recommended that this refer only to the extraprostatic part of the seminal vesicle. ${ }^{13} \mathrm{In}$ some patients, the clinician will specifically target the seminal vesicles during the biopsy procedure and submit these as a separate specimen. In such cases, if tumor is recognized within the smooth muscle wall of seminal vesicle tissue it should be reported as such (Figure 5a). Biopsies designated as 'seminal vesicle' can however have tumor in prostatic tissue or in the peri-seminal vesicle soft tissue and when this is present the report must clearly indicate that the adenocarcinoma is present in the specimen but not in the seminal vesicle tissue (if present) (Figure 5b). Biopsies of the prostate gland, most often from the base, may contain tissue that could represent either seminal vesicle or ejaculatory duct. In such cases if the tissue is involved by the adenocarcinoma this should be commented on but a note should indicate that this may not represent seminal vesicle for staging purposes. ${ }^{8}$

\section{Lymphovascular Invasion}

Lymphovascular invasion as a prognostic feature has been studied in radical prostatectomy specimens 

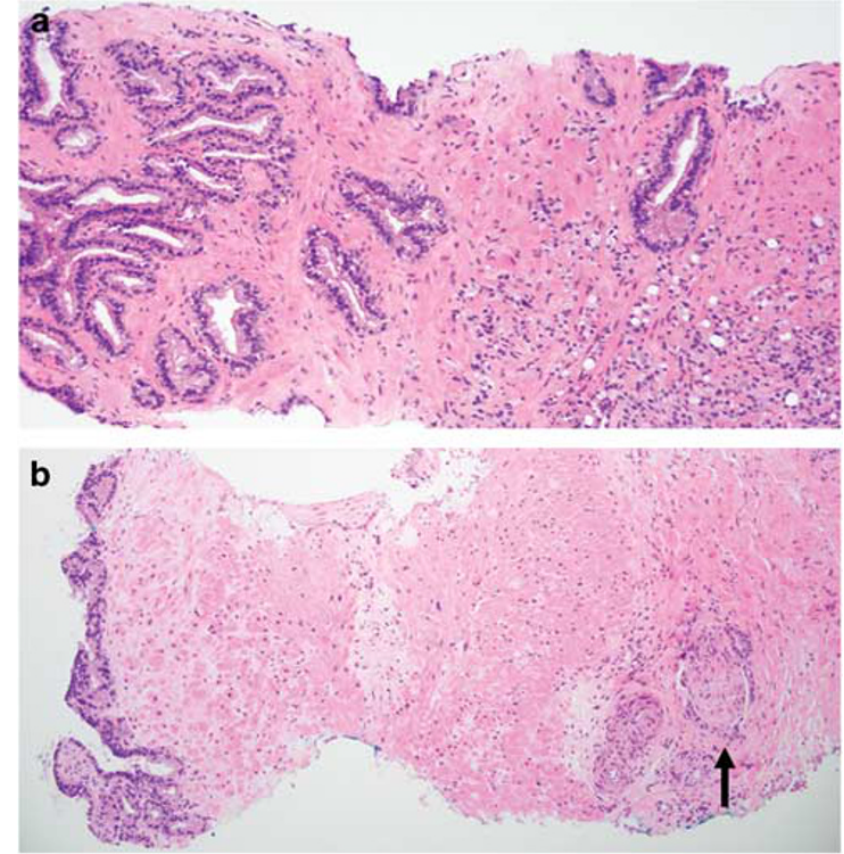

Figure 5 In a biopsy submitted as coming from the seminal vesicle (a), involvement of the seminal vesicle tissue is present. In a second seminal vesicle biopsy (b) there is perineural tumor (arrow) in the soft tissue adjacent to the muscular wall but not in the seminal vesicle wall. Reporting a case such as this needs to be clear to indicate that although the specimen contains adenocarcinoma and seminal vesicle tissue, the seminal vesicle tissue is not involved by the tumor.

(see below) but there is little data available for needle biopsies. Experience of most urologic pathologists has been that this is a quite unusual finding in needle biopsies, even with high-volume and high-grade disease. Because of the lack of data, this is included as a non-required or recommended element. ${ }^{6-8}$

\section{Perineural Invasion}

Reporting the presence or absence of perineural invasion is not a required element in either the College of American Pathologists or the International Collaboration on Cancer Reporting guidelines. ${ }^{6,7}$ The significance of perineural invasion in needle biopsy specimens has been extensively studied, with the general conclusion that although it is a significant predictor of pathologic stage and outcome after radical prostatectomy on univariate analysis, it is not an independent factor on multivariable analysis. ${ }^{31,32}$ A more recent report, based on the evaluation of 3226 patients, found perineural invasion to be present in the biopsies of $20 \%$ of those undergoing radical prostatectomy. ${ }^{33}$ In that large series, it was independently associated with adverse pathologic findings (extraprostatic extension, seminal vesicle invasion, and positive surgical margins) in the radical prostatectomy specimen. It was also an independent predictor of biochemical disease-free survival, cancer-specific survival, and overall survival. One recent report in MR/US fusion biopsies found perineural invasion to be an independent predictor of extraprostatic extension. ${ }^{34}$ The significance of perineural invasion in men otherwise eligible for active surveillance has been studied. In an analysis of radical prostatectomy specimens from men eligible for active surveillance, Trpkov et $a .^{35}$ found no increase in adverse pathologic findings in patients with perineural invasion in the biopsy compared with those without. In another report, Moreira et al. ${ }^{36}$ found a significantly higher clinical progression for men on active surveillance with perineural invasion versus those without. Should future studies support the latter finding it may be that perineural invasion will be included as a required element. In current guidelines it is a nonrequired or recommended element. ${ }^{6,8}$

\section{Additional Pathologic Findings}

A wide range of other histopathologic abnormalities can be present in prostatic biopsies, including highgrade prostatic intraepithelial neoplasia, atrophy, and inflammatory processes. In the presence of adenocarcinoma, there is no data to indicate clinical significance to any of these.

\section{Radical prostatectomy specimens}

\section{Prostate Size}

The most recent College of American Pathologists guidelines no longer include prostate gland measurements as a required element in the synoptic summary. ${ }^{6}$ The International Collaboration on Cancer Reporting does include weight but not dimensions as a required element. ${ }^{9}$ This recognizes that measurements (dimensions and weight) are an essential part of the gross description and so it is not necessary to repeat them in this part of the report.

\section{Tumor Quantitation}

- Percentage of prostate involved by tumor

- And/or

- Greatest dimension (mm)

- *Additional dimensions (mm)

The significance of quantitation of tumor in the radical prostatectomy specimen has been an area of considerable debate among urological pathologists. Because of the nature of prostatic adenocarcinoma with tumor multifocality and frequent growth without formation of a distinct solid mass, determination of actual tumor volume has long been viewed as problematic. A number of approaches, including eyeball estimation, use of a grid system, image analysis, measuring the proportion of blocks with tumor, measuring the maximum tumor dimension, and others have been described. ${ }^{11}$ There is substantial data indicating that 
tumor volume predict pathologic stage, biochemical failure, and development of metastases. ${ }^{37-39}$ Studies evaluating the greatest dimension of the tumor as a surrogate for volume have also found it to be a significant predictor of pathologic stage and outcome. ${ }^{40,41}$ In the International Society of Urological Pathology review of this topic, the authors concluded that although cancer volume correlated with may important parameters, there were insufficient data to conclude it was an independent predictor of outcome in contemporary studies. It is however certain that our clinical colleagues have considerable interest in the information. This remains a required element in College of American Pathologists guidelines; ${ }^{6}$ it is not required but recommended in the International Collaboration on Cancer Reporting data set. ${ }^{7,9}$

\section{Extraprostatic Extension}

Focal or nonfocal (if present). The presence of extraprostatic extension defines the pT3a category in the pathologic staging of prostatic adenocarcinoma.
The presence of extraprostatic extension is associated with an increased risk of biochemical recurrence, distant metastases and cancer-specific survival. It is therefore a required element in both the College of American Pathologists and the International Collaboration on Cancer Reporting guidelines. ${ }^{6,7,9}$ The assessment of extraprostatic extension is made challenging by the fact that the prostate gland for the most part does not have a welldefined capsule. ${ }^{42}$ The most straightforward criteria for extraprostatic extension is invasion into periprostatic fat (Figure 6a). The rare occurrence of fat within the prostate gland discussed above is not problematic in the radical prostatectomy specimen. Extraprostatic extension is also diagnosed when there is clear extension beyond the confines of the prostate. This includes extension along fibrous bands or nerves within the periprostatic tissue (Figure 6b). ${ }^{12}$ In many prostate glands there is condensation of the muscular stroma at the gland periphery with a loose often non-muscle containing stroma beyond (Figure 6c). Involvement of this
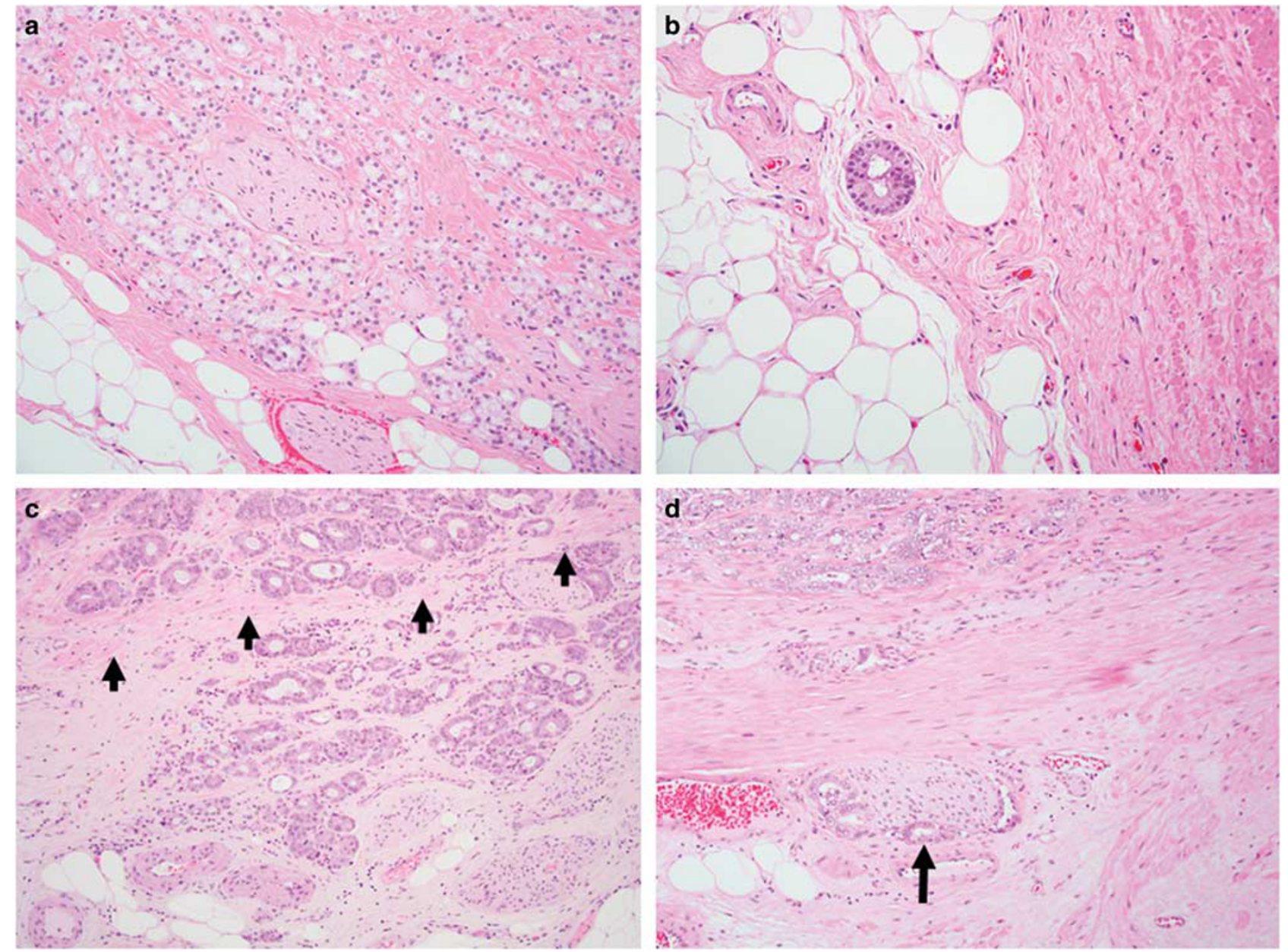

Figure 6 These images illustrate foci of extraprostatic extension. In a the tumor is directly involving fat. In $\mathbf{b}$ there is a single malignant gland in fibrous connective tissue within the fat. The image in $\mathbf{c}$ shows tumor in loose fibrous connective tissue beyond the boundary where smooth muscle fiber (arrows) end. In image $\mathbf{d}$ there is a focus of perineural tumor (arrow) adjacent to (at the level of) fat. 
stroma, with or without associated desmoplasia, can also be used to support the presence of extraprostatic extension. In this situation, the presence of fat at the same level adjacent to the tumor will help support the diagnosis (Figure 6d)., ${ }^{7,9}$ The apex and the anterior aspect of the prostate are particularly problematic. Involvement of the apex is not by definition extraprostatic extension, including cases where the tumor is present at the margin. ${ }^{12}$ Anteriorly, there is a paucity of glands and the anterior fibromuscular stroma as described by $\mathrm{McNeal}^{43}$ does not have a defined capsule. Using a 'guesstimated' contour joining benign glandular elements has been discussed, but given the anatomy of the anterior prostate gland, this would not be reliable. For these reasons, fat involvement is the most important criteria for extraprostatic extension at this location. Both the apex and anterior prostate contain skeletal muscle and this is not a useful indicator of extraprostatic extension. It has however been reported that the presence of tumor in skeletal muscle in apex biopsies is associated with an increased risk of a positive surgical margin at the apex. ${ }^{44}$

Studies evaluating the reproducibility of the diagnosis of extraprostatic extension have highlighted the difficulties pathologists face. ${ }^{45-47}$ The major difficulty these studies have highlighted is handling cases where the extraprostatic extension is equivocal (Figure 7). ${ }^{47}$ The AJCC Cancer Staging manual provides guidance for these cases. The general staging rules state that 'If uncertainty exists regarding how to assign a category, subcategory, or stage group, the lower of the two possible categories, subcategories, or groups is assigned for T, N, or M. ${ }^{48}$ On the basis of this principle, if a focus is equivocal

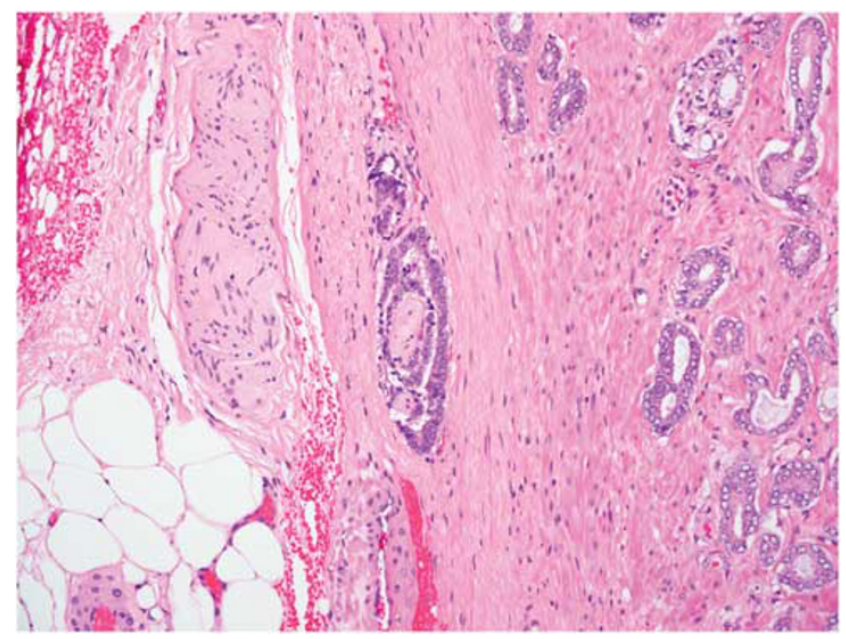

Figure 7 This photomicrograph shows perineural adenocarcinoma in dense fibrous tissue at the apparent edge of the prostate gland. There is not a well-defined condensation of smooth muscle in the area and there is no stromal response to the tumor. If uncertain as to whether this should be considered extraprostatic extension or not, the AJCC rules for staging would indicate that as it is not unequivocally extraprostatic extension it should be considered organ confined (pT2). for extraprostatic extension, the tumor should be assigned to the pT2 category (all other things being equal).

Quantification of extraprostatic extension has been demonstrated to have prognostic significance. ${ }^{49-54}$ Two basic approaches have been used. The first defines focal using quantification of the tumor beyond the gland ${ }^{49,50,54}$ while the second uses measuring the radial extension beyond the gland.51-54 Either approach has demonstrated the significance of quantifying extraprostatic extension. The current College of American Pathologists and the International Collaboration on Cancer Reporting recommend using only a few neoplastic glands being outside the prostate or a tumor involving less than one high-power field $(\times 40)$ in one or two sections to define focal extraprostatic extension with nonfocal being more than this. ${ }^{6,7,9}$

Urinary bladder neck invasion. Before the seventh edition of the AJCC Cancer Staging Manual, ${ }^{55}$ the staging of tumors with microscopic involvement of the bladder neck in the radical prostatectomy specimen was controversial. Some considered this to be pT4 (bladder invasion) while others considered it to be 'specimen confined' and not to affect assignment of $\mathrm{T}$. In the seventh edition this was resolved with microscopic involvement of the bladder neck included in the definition of extraprostatic extension (pT3a). ${ }^{55}$ This definition is retained in the eighth edition. ${ }^{48}$ The change was based on data indicating that biochemical recurrence for cases with microscopic involvement of the bladder neck was similar to cases with extraprostatic extension. ${ }^{56-61}$ These studies are however confounded by the inclusion of cases with a positive bladder neck margin in the bladder neck invasion definition. ${ }^{56,62}$

The definition of bladder neck invasion as described in the AJCC manual is 'tumor detected in bladder neck/proximal margin sections. ${ }^{48}$ This is problematic as depending on how the prostate gland is dissected, these 'sections' frequently contain prostatic glandular tissue. A more practical approach is to define bladder neck invasion as the presence of prostatic adenocarcinoma in thick smooth muscle bundles in the absence of benign prostatic glands (Figure 8a). ${ }^{7,9}$ If benign prostatic glands are present, then this should not be considered bladder neck invasion, even if the block comes from the bladder neck region (Figure 8b). ${ }^{12,63}$

Seminal vesicle invasion. The presence of seminal vesicle invasion defines the pT3b category in the pathologic staging of prostatic adenocarcinoma. ${ }^{48}$ Invasion of the seminal vesicle(s) indicates a worse prognosis than extraprostatic extension. ${ }^{64,65}$ By definition, seminal vesicle invasion requires demonstration of invasion of the muscular wall and is limited to the extraprostatic portion of the seminal vesicle (Figure 9a). ${ }^{13,48}$ Tumor present in the periseminal vesicle soft tissue should be reported as 

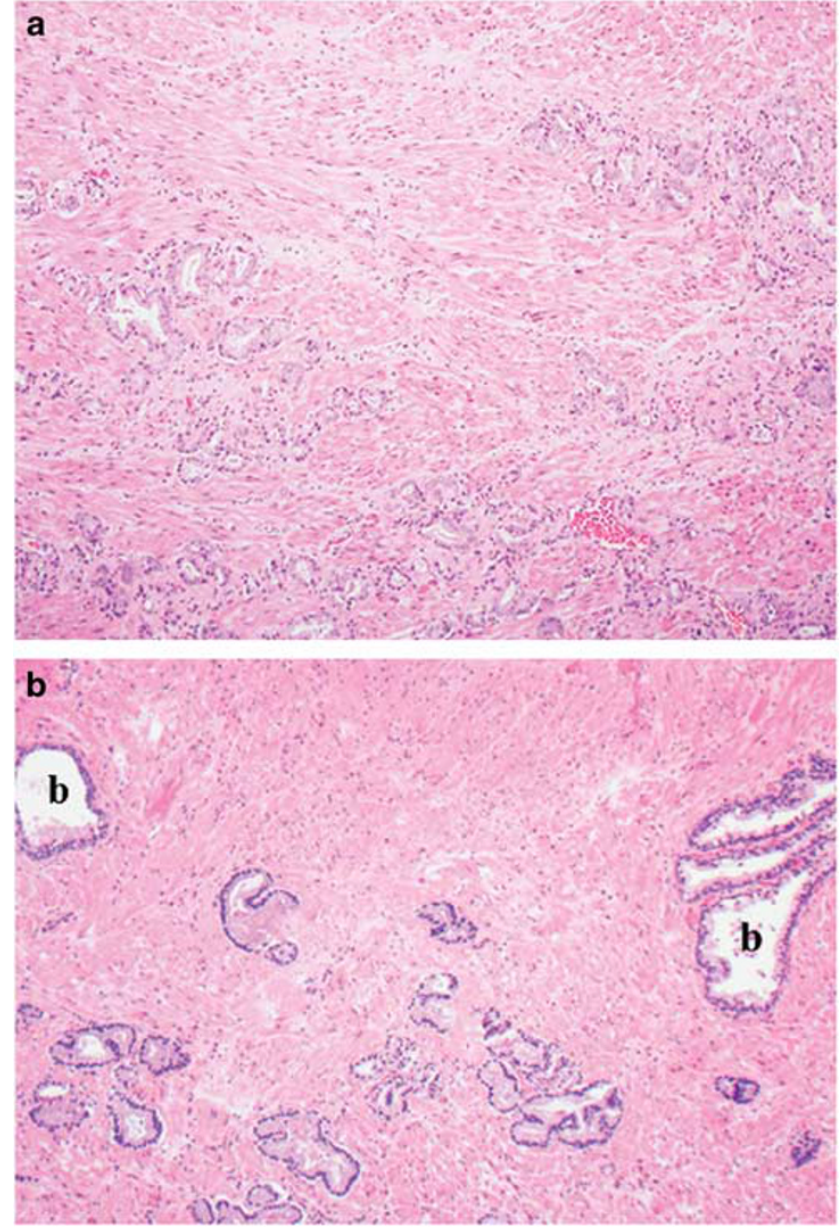

Figure $8 \mathrm{In}$ this section from the bladder neck (a) tumor is invading smooth muscle fibers without associated benign prostatic glands. This is considered to be pT3a disease in the current AJCC TNM staging system. In contrast, the bladder neck section in $\mathbf{b}$ also has tumor but in this case there are intermingled benign glands (b) and so it should not be assigned to the pT3a category.

extraprostatic extension, not seminal vesicle invasion (Figure 9b). Prostatic adenocarcinoma has been shown to involve the seminal vesicles by different routes, including direct invasion at the prostatic stroma/seminal vesicle junction, extension along the ejaculatory ducts, by invasion from extraprostatic tumor and finally indirectly, presumably by metastases. ${ }^{66}$ This has implications for sampling of the seminal vesicles; it is generally agreed that a section taken at the junction of the seminal vesicle and the prostatic gland is the one most likely to detect seminal vesicle invasion. ${ }^{13}$ Additional random sections or sections grossly suspicious for tumor may also be submitted. Total submission of the seminal vesicles is not considered necessary. ${ }^{13}$

\section{Margins}

- Limited ( $<3 \mathrm{~mm})$ or non-limited $(\geq 3 \mathrm{~mm})$

- *Linear length of positive margins

- *Focality (unifocal or multifocal)
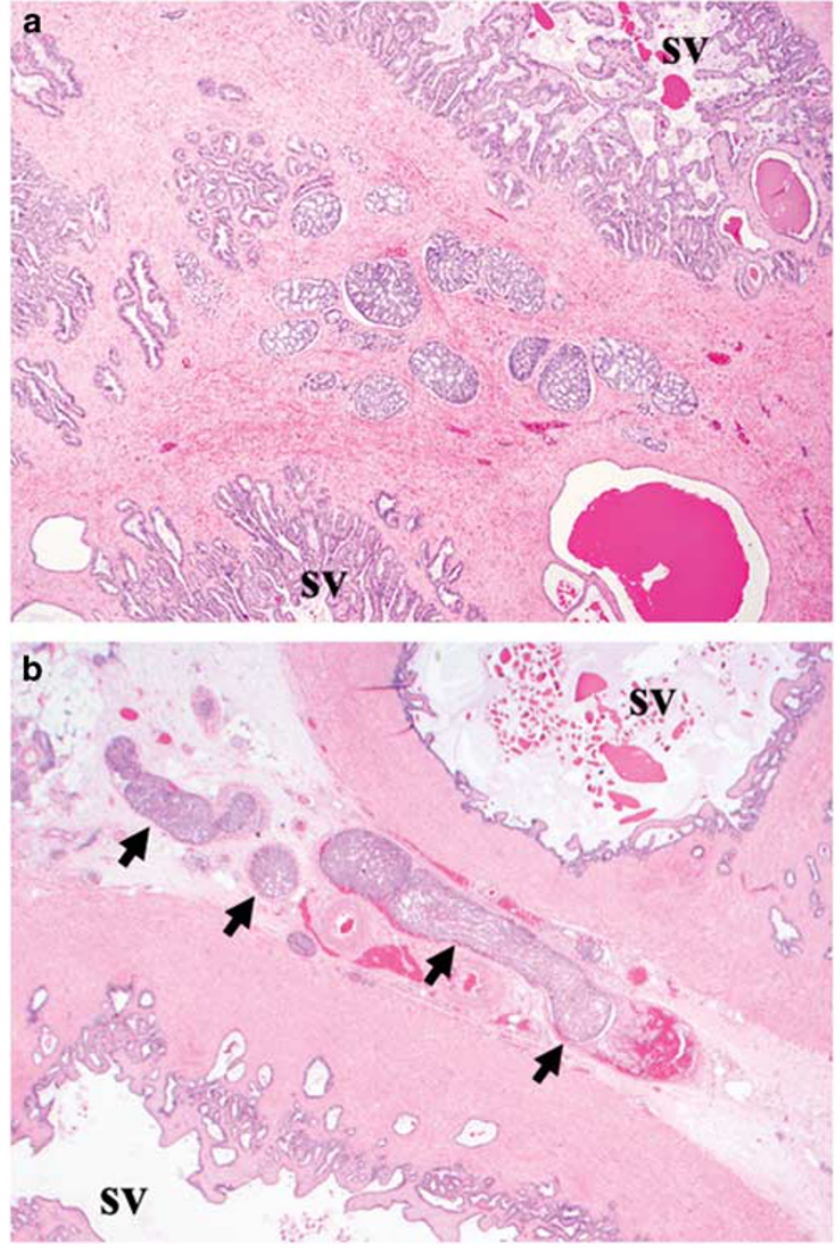

Figure 9 In image a the tumor is extensively infiltrating the muscular wall of the seminal vesicle meeting the criteria for pT3b disease. In the second image (b) there is tumor present between the muscular walls of the seminal vesicle (arrows) that is largely within lymphovascular spaces. This should not be diagnosed as seminal vesicle invasion.

- Location(s) of positive margin

- *Margin positivity at area of extraprostatic extension

- *Gleason pattern at positive margin.

The presence of carcinoma at the surgical margin is well documented to have independent prognostic significance following radical prostatectomy. ${ }^{14} \mathrm{~A}$ positive surgical margin is defined by the presence of tumor touching the inked surface of the specimen (Figure 10a). ${ }^{7,14}$ The presence of even one or two collagen fibers between the tumor and the ink is enough to consider the margin negative (Figure 10b). ${ }^{7}$ It is generally accepted that the closeness of the tumor to the margin does not have prognostic significance based on most reports in the literature though this has not been uniformly found. ${ }^{67,68}$ In some cases the degree of cautery at the margin can make interpretation difficult; if tumor is extending into the cauterized tissue it should be considered to represent a positive margin (Figure 10c). 

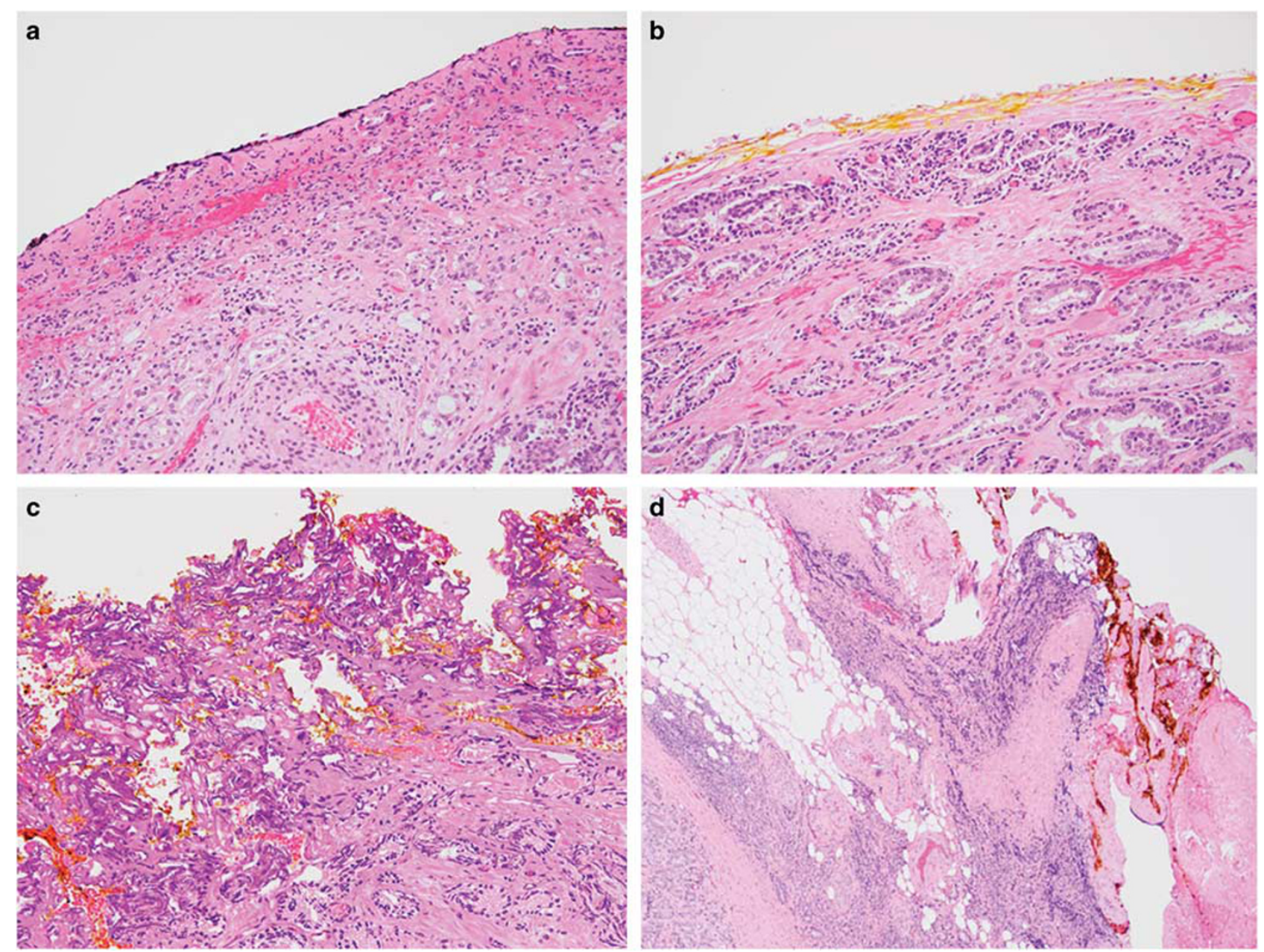

Figure 10 In the first image (a) there is tumor extending directly to the inked surface meeting the definition of a positive surgical margin. In image $\mathbf{b}$ the tumor is very close but does not actually touch the ink and this would be reported as a negative surgical margin. In $\mathbf{c}$ obvious tumor is extending into the inked cauterized surface; this is considered a positive surgical margin. Image $\mathbf{d}$ illustrates and example of tumor involving the inked cauterized margin at a site of extraprostatic extension.

In cases with positive surgical margins several additional parameters have been evaluated in the literature, including the location of the positive margin, quantification of the positive margin (linear length in $\mathrm{mm}$ ), whether is unifocal or multifocal, whether it is at a site of extraprostatic extension or not, and the Gleason score of the tumor at the margin. Some reports have found that specific locations are associated a with a higher failure rate but other studies have found different (conflicting) locations while others have found location to not matter. ${ }^{69-74}$ Nonetheless, both the College of American Pathologists and the International Collaboration on Cancer Reporting list the location of positive $\operatorname{margin}(\mathrm{s})$ as a required element. ${ }^{6,9}$

The data regarding quantification of the extent of surgical margin positivity have been more consistent. ${ }^{69,75-82}$ In several reports, a total length of $3 \mathrm{~mm}$ was found to be a useful cut point, ${ }^{74,76,78,80,82}$ and this has been adopted by the College of American Pathologists to define 'limited' and 'non-limited' involvement. ${ }^{6}$ The International Collaboration on Cancer Reporting has also adopted the $3 \mathrm{~mm}$ cut point but includes this as a recommended but not required element. ${ }^{9}$

It has also been reported that the presence of tumor at the inked margin at the site of extraprostatic extension confers a particularly higher risk of subsequent failure although data here are very limited (Figure 10d). ${ }^{83} \mathrm{~A}$ detailed study of the distance of the extraprostatic tumor to the adjacent margin did not find this to impact outcome. ${ }^{84} \mathrm{~A}$ special situation arises when tumor is at the margin in combination with benign glands. Published data indicates that positive margins at a site of 'intraprostatic incision' or 'capsular incision' is associated with a higher risk of failure than positive surgical margins in a pT2 tumor. ${ }^{78,85,86}$

Finally, several reports have looked at the Gleason score of the tumor at the site of the positive surgical margin(s). ${ }^{75,79,82,87}$ These have found the tumor grade at the positive margin to be an independent 
predictor of biochemical recurrence. Given the limited data, reporting this feature is at present not a required element in either the College of American Pathologists or International Collaboration on Cancer Reporting guidelines. ${ }^{6,7,9}$

Lymphovascular invasion. The prognostic significance of lymphovascular invasion as a finding in radical prostatectomy specimens has been recognized for many years. ${ }^{88,89}$ This has been confirmed in several large (number of cases ranging from 742 to 6678) contemporary series based on examination of the hematoxylin-and-eosin-stained slides. ${ }^{76,90-94}$ In these series lymphovascular invasion was identified in $2.8-21.5 \%$ of specimens (median, $7.4 \%$ ). In all six large contemporary series, the presence of lymphovascular invasion was an independent predictor of biochemical recurrence on multivariable analysis. In general the presence of lymphovascular invasion is considered to be relatively uncommon, with the exception of the one series. ${ }^{92}$ Problems with histologic criteria for lymphovascular invasion in prostatectomy specimens have been reported on and strict criteria need to be applied in these specimens. ${ }^{12,95}$ Interestingly, in one series unequivocal and equivocal lymphovascular invasion were analyzed separately and both were independent predictors of biochemical recurrence. ${ }^{91}$ Despite the strong data in the literature, this element is not required in the College of American Pathologists or the International Collaboration on Cancer Reporting protocols. ${ }^{6,7,9}$

Perineural invasion. The clinical significance of perineural invasion in the radical prostatectomy specimen has been evaluated in multiple studies. ${ }^{76,90}$ Perineural invasion is present in the majority of radical prostatectomy specimens. It has generally been accepted that perineural invasion in the radical prostatectomy specimen is not an independent predictor of outcome after surgery, ${ }^{6}$ and therefore it has not been a required element for reporting guidelines. There have been some studies to indicate otherwise but to date these have been in the minority. ${ }^{90}$

Regional lymph nodes. A regional lymph node dissection may or may not be performed at the time of radical prostatectomy depending on surgeon preference and some assessment of likelihood of lymph node metastases being detected. When a lymph node dissection is submitted, quantification of the number of lymph nodes present is considered a required element in the report. ${ }^{6,7,9,13}$ In the current AJCC staging system there are only two $\mathrm{N}$ categories that apply: No, no positive regional nodes; and N1, metastases in regional node(s). ${ }^{48}$ The number of positive lymph nodes and the size of metastases are not part of the nodal category. Involvement of nonregional lymph nodes is reported as pM1a. ${ }^{48}$

Although not part of the $\mathrm{N}$ category, determination of the number of nodes with metastases is a required element. The number of positive lymph nodes is an independent predictor of survival in these patients. ${ }^{96}$ Other features such as the size ( $\mathrm{mm}$ ) of the largest metastasis, the size of the largest involved lymph node $(\mathrm{cm})$, and the presence or absence of extranodal extension are not required elements. ${ }^{6,7,9}$ The size of metastatic deposits has been reported to be a significant predictor of biochemical recurrence-free survival, distant metastasis, and cancer-specific survival in some but not all reports (Figure 11a). ${ }^{96-}$ 99 The International Society of Urological Pathology did however recommend reporting the size of the largest deposit. ${ }^{13}$

There are limited numbers of reports on the significance of extranodal extension in patients with lymph node metastases (Figure 11b). One series of 484 patients with lymph node metastases found extranodal extension in $58 \%$ of cases; this correlated significantly with biochemical recurrence-free survival in a univariate but not a multivariate analysis. ${ }^{96}$ A recent meta-analysis of six publications considered suitable for inclusion, reported extranodal extension to correlate significantly with a higher risk of biochemical recurrence and distant metastases. ${ }^{100}$ Interestingly, a survey of members of the International Society of Urological Pathology
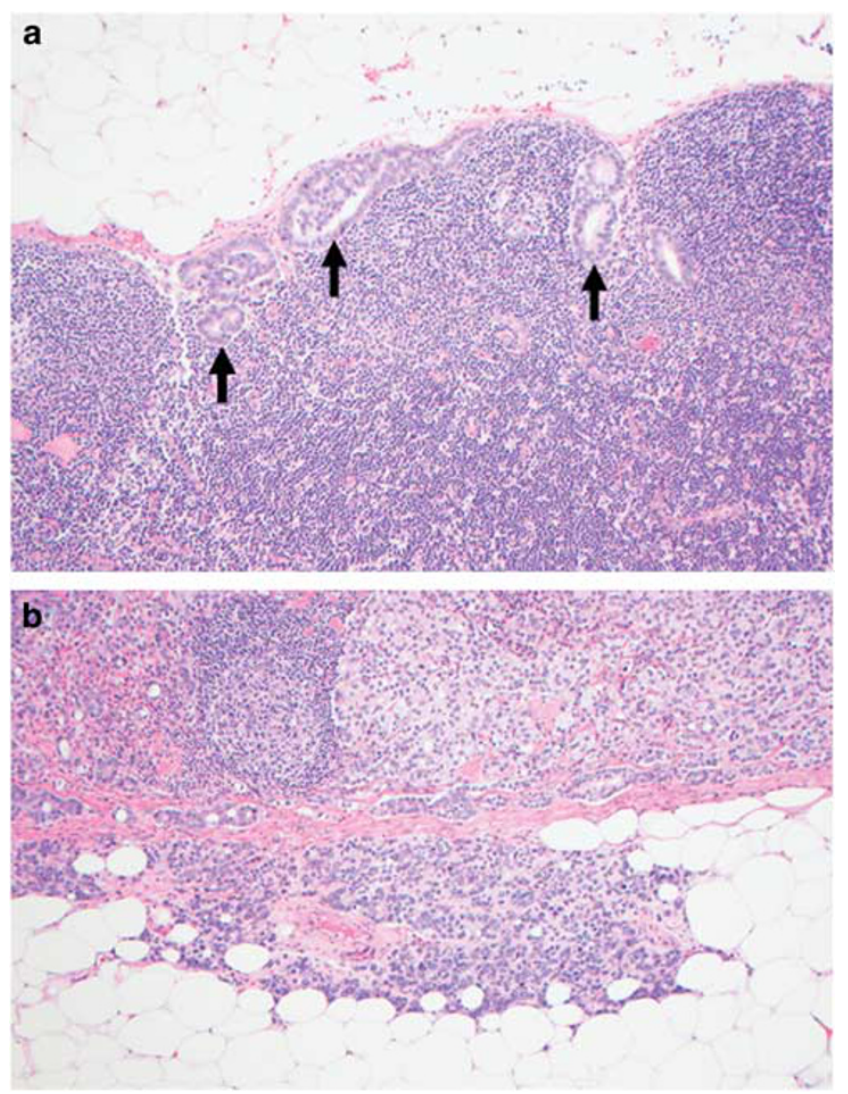

Figure 11 The first photomicrograph (a) illustrates a lymph node with a microscopic metastases consisting of only a few malignant glands. In contrast image b shows a large lymph node metastasis that also has extranodal extension of the tumor. 
Table 3 Pathologic stage classification (pTNM AJCC eighth edition $)^{48}$

$\begin{array}{cl}\text { Pathological T category }(p T) \\ \text { pT2 } & \text { Organ confined } \\ \text { pT3a } & \text { Extraprostatic extension (unilateral or bilateral) or } \\ & \text { microscopic invasion of bladder neck } \\ \text { pT3b } & \text { Tumor invades seminal vesicle(s) } \\ \text { pT4 } & \text { Tumor is fixed or invades adjacent structures other } \\ & \text { than seminal vesicles such as external sphincter, } \\ & \text { rectum, bladder, levator muscles, and/or pelvic wall }\end{array}$

Regional lymph nodes $(N)$

NX Regional nodes were not assessed

No No positive regional nodes

N1 Metastasis in regional node(s)

Distant metastasis (M)

Mo No distant metastasis

M1 Distant metastasis

M1a Nonregional lymph node(s)

M1b Bone metastasis

M1c Other site(s) with or without bone disease

found that $88 \%$ of respondents did report extranodal extension. ${ }^{13}$

\section{Disclosure/conflict of interest}

The author declares no conflict of interest.

\section{References}

1 Amin MB, Lin DW, Gore JL, et al. The critical role of the pathologist in determining eligibility for active surveillance as a management option in patients with prostate cancer: consensus statement with recommendations supported by the College of American Pathologists, International Society of Urological Pathology, Association of Directors of Anatomic and Surgical Pathology, the New Zealand Society of Pathologists, and the Prostate Cancer Foundation. Arch Pathol Lab Med 2014;138:1387-1405.

2 Stavrinides V, Parker C, Moore C. When no treatment is the best treatment: active surveillance strategies for low risk prostate cancers. Cancer Treat Rev 2017;58: 14-21.

3 Savdie R, Aning J, So A, et al. Identifying intermediate-risk candidates for surveillance of prostate cancer. Urol Oncol 2017;35:605.e1-605.e8.

4 Dess R, Morgan T, Nguyen P et al.. Adjuvant versus early salvage radiation therapy following radical prostatectomy for men with localized prostate cancer. Curr Urol Rep 2017;18:55.

5 Aoun F, Bourgi A, Ayoub E, et al. Androgen deprivation therapy in the treatment of locally advanced, nonmetastatic prostate cancer: practical experience and a review of the clinical trial evidence. Ther Adv Urol 2017;9:73-80.

6 Srigley J, Zhou M, Allan R, et al. Protocol for the examination of specimens from patients with carcinoma of the prostate gland. College of American Pathologists: Chicago IL, USA, 2017 (posted).

7 Kench JG, Delahunt B, Griffiths DF, et al. Dataset for reporting of prostate carcinoma in radical prostatectomy specimens: recommendations from the International Collaboration on Cancer Reporting. Histopathology 2013;62:203-218.

8 Egevad L, Kench J, Delahunt B, et al. Prostate Core Needle Biopsy Histopathology Reporting Guide, 1st edn. International Collaboration on Cancer Reporting: Sydney, Australia, 2017.

9 Egevad L, Kench J, Delahunt B, et al. Prostate Cancer, Radical Prostatectomy, Histopathology Reporting Guide, 2nd edn. International Collaboration on Cancer Reporting: Sydney, Australia, 2017.

10 Samaratunga H, Montironi R, True L, et al. International Society of Urological Pathology (ISUP) consensus conference on handling and staging of radical prostatectomy specimens. Work group 1: specimen handling. Mod Pathol 2011;24:6-15.

11 van der Kwast T, Amin M, Billis A, et al. International Society of Urological Pathology (ISUP) consensus conference on handling and staging of radical prostatectomy specimens. Working group 2: substaging and prostate cancer volume. Mod Pathol 2011:24:16-25.

12 Magi-Galluzzi C, Evans A, Delahunt B, et al. International Society of Urological Pathology (ISUP) consensus conference on handling and staging of radical prostatectomy specimens. Working group 3: extraprostatic extension, lymphovascular invasion and locally advanced disease. Mod Pathol 2011;24:26-38.

13 Berney D, Wheeler T, Grignon D, et al. International Society of Urological Pathology (ISUP) consensus conference on handling and staging of radical prostatectomy specimens. Working group 4: seminal vesicles and lymph nodes. Mod Pathol 2011;24: 39-47.

14 Tan P, Cheng L, Srigley J, et al. International Society of Urological Pathology (ISUP) consensus conference on handling and staging of radical prostatectomy specimens. Working group 5: surgical margins. Mod Pathol 2011:24:48-57.

15 Sebo T, Bock B, Cheville J, et al. The percent of cores positive for cancer in prostate needle biopsy specimens is strongly predictive of tumor stage and volume at radical prostatectomy. J Urol 2000;163:174-178.

16 Bismar T, Lewis JJ, Vollmer R, et al. Multiple measures of carcinoma extent versus perineural invasion in prostate needle biopsy tissue in prediction of pathologic stage in a screening population. Am J Surg Pathol 2003;27:432-440.

17 Poulos C, Daggy J, Cheng L. Prostate needle biopsies: multiple variables are predictive of final tumor volume in radical prostatectomy specimens. Cancer 2004;101:527-532.

18 Brimo F, Vollmer R, Corcos J, et al. Prognostic values of various morphometric measurements of tumour extent in prostate needle core tissue. Histopathology 2008;53:177-183.

19 D'Amico AV, Keshaviah A, Manola J, et al. Clinical utility of the percentage of positive prostate biopsies in predicting prostate cancer-specific and overall survival after radiotherapy for patients with localized prostate cancer. Int J Rad Oncol Biol Phys 2002;53: 581-587.

20 D'Amico A, Whittington R, Malkowicz S, et al. Biochemical outcome after radical prostatectomy or external beam radiation therapy for patients with clinically localized prostate carcinoma in the prostate specific antigen era. Cancer 2002;95:281-286. 
21 Schultz L, Maluf C, da Silva R, et al. Discontinuous foci of cancer in a single core of prostatic biopsy: when it occurs and performance of quantification methods in a private-practice setting. Am J Surg Pathol 2013;37:1831-1836.

22 Karram S, Trock B, Netto G, et al. Should intervening benign tissue be included in the measurement of discontinuous foci of cancer on prostate needle biopsy? Correlation with radical prostatectomy findings. Am J Surg Pathol 2011;35:1351-1355.

23 Arias-Stella J, Varma K, Montoya-Cerrilo D, et al. Does discontinuous involvement of a prostatic needle biopsy core by adenocarcinoma correlate with large tumor focus at radical prostatectomy? Am J Surg Pathol 2015;39:281-286.

24 Ravery V, Boccon-Gibod L, Dauge-Geffroy M, et al. Systematic biopsies accurately predict extracapsular extension of prostate cancer and persistent/recurrent detectable PSA after radical prostatectomy. Urology 1994;44:371-376.

25 Miller J, Chen Y-b YeH, Robinson B, et al. Extraprostatic extension of prostatic adenocarcinoma on needle core biopsy: report of 72 cases with clinical follow-up. BJU Int 2010;106:330-333.

26 Cohen R, Stables S. Intraprostatic fat. Hum Pathol 1998;29:424-425.

27 Billis A. Intraprostatic fat: does it exist? Hum Pathol 2004;35:525.

28 Sung M, Eble J, Cheng L. Invasion of fat justifies assignment of stage pT3a in prostatic adenocarcinoma. Pathology 2006;38:309-311.

29 Nazeer T, Kee K, Ro J, et al. Intraprostatic adipose tissue: a study of 427 whole mounted radical prostatectomy specimens. Hum Pathol 2009;40: 538-541.

30 Joshi A, Shah V, Varma M. Intraprostatic fat in a prostatic needle biopsy: a case report and review of the literature. Histopathol 2009;54:912-913.

31 Harnden P, Shelley MD, Clements $\mathrm{H}$, et al. The prognostic significance of perineural invasion in prostatic cancer biopsies: a systematic review. Cancer 2007;109:13-24.

32 Loeb S, Epstein J, Humphreys E, et al. Does perineural invasion on prostate biopsy predict adverse prostatectomy outcomes? BJU Int 2010;105:1510-1513.

33 DeLancey J, Wood DJ, He C, et al. Evidence of perineural invasion on prostate biopsy specimen and survival after radical prostatectomy. Urology 2013;81:354-357.

34 Truong M, Rais-Bahrami S, Nix J, et al. Perineural invasion by prostate cancer on MR/US fusion targeted biopsy is associated with extraprostatic extension and early biochemical recurrence after radical prostatectomy. Hum Pathol 2017;66:206-211.

35 Trpkov C, Yilmaz A, Trpkov K. Perineural invasion in prostate cancer patients who are potential candidates for active surveillance: validation study. Urology 2014;84:149-152.

36 Moreira D, Fleshner N, Freedland S. Baseline perineural invasion is associated with shorter time to progression in men with prostate cancer undergoing active surveillance: results from the REDEEM study. J Urol 2015;194:1258-1263.

37 Humphrey P, Vollmer R. Intraglandular tumor extent and prognosis in prostatic adenocarcinoma: application of a grid method to prostatectomy specimens. Hum Pathol 1990;21:799-804.
38 Stamey T, McNeal J, Yemoto C, et al. Biological determinants of cancer progression in men with prostate cancer. JAMA 1999;281:1395-1400.

39 Salomon L, Levrel O, Anastasiadis A, et al. Prognostic significance of tumor volume after radical prostatectomy: a multivariate analysis of pathological prognostic factors. Eur Urol 2003;43:39-44.

40 Eichelberger L, Koch M, Eble J, et al. Maximum tumor diameter is an independent predictor of prostatespecific antigen recurrence in prostate cancer. Mod Pathol 2005;18:886-890.

41 Dvorak T, Chen M, Renshaw A, et al. Maximal tumor diameter and the risk of PSA failure in men with specimen-confined prostate cancer. Urology 2005;66: 1024-1028.

42 Ayala AG, Ro JY, Babaian R, et al. The prostatic capsule: does it exist? Its importance in the staging and treatment of prostatic carcinoma. Am J Surg Pathol 1989;13:21-27.

$43 \mathrm{McNeal}$ J. The zonal anatomy of the prostate. Prostate 1981;2:35-49.

44 Sadimin E, Ye H, Epstein J. Should involvement of skeletal muscle by prostatic adenocarcinoma be reported on biopsies? Am J Surg Pathol 2016;49: 10-14.

45 Ekici S, Ayhan A, Erkan I, et al. The role of the pathologist in the evaluation of radical prostatectomy specimens. Scand J Urol Nephrol 2003;37: 387-391.

46 van der Kwast TH, Collette L, Van Poppel H, et al. Impact of pathology review of stage and margin status of radical prostatectomy specimens (EORTC trial 22911). Virchows Arch 2006;449:428-434.

47 Evans AJ, Henry PC, Van der Kwast TH, et al. Interobserver variability between expert urologic pathologists for extraprostatic extension and surgical margin status in radical prostatectomy specimens. Am J Surg Pathol 2008;32:1503-1512.

48 Amin B, Edge S, Greene F, et al. (eds) AJCC Cancer Staging Manual, 8th edn. Springer: Chicago, IL, USA, 2017.

49 Epstein JI, Carmichael MJ, Pizov G, et al. Influence of capsular penetration on progression following radical prostatectomy: a study of 196 cases with long-term followup. J Urol 1993;150:135-141.

50 Wheeler TM, Dillioglugil O, Kattan MW, et al. Clinical and pathological significance of the level and extent of capsular invasion in clinical stage T1-2 prostate cancer. Hum Pathol 1998;29:856-862.

51 Davis B, Pisansky T, Wilson T, et al. The radial distance of extraprostatic extension of prostate carcinoma: implications for prostate brachytherapy. Cancer Treat Rev 1999;85:2630-2637.

52 Sohayda C, Kupelian P, Levin H, et al. Extent of extracapsular extension in localized prostate cancer. Urology 2000;55:382-386.

53 Sung M, Lin H, Koch M, et al. Radial distance of extraprostatic extension measured by ocular micrometer is an independent predictor of prostate-specific antigen recurrence: a new proposal for the substaging of pT3a prostate cancer. Am J Surg Pathol 2007;31: 311-318.

54 van Veggel B, van Oort I, Witjes J, et al. Quantification of extraprostatic extension in prostate cancer: different parameters correlated to biochemical recurrence after radical prostatectomy. Histopathology 2011;59: 692-702. 
55 Edge S, Byrd D, Compton C, et al. (eds). AJCC Cancer Staging Manual, 7th edn. Springer: New York, NY, USA, 2010.

56 Pierorazio PM, Epstein JI, Humphreys E, et al. The significance of a positive bladder neck margin after radical prostatectomy: the American Joint Committee on Cancer Pathological Stage T4 designation is not warranted. J Urol 2010;183:151-157.

57 Yossepowitch O, Sircar K, Scardino P, et al. Bladder neck involvement in pathological stage pT4 radical prostatectomy specimens is not an independent prognostic factor. J Urol 2002;168:2011-2015.

58 Dash A, Sanda M, Yu M, et al. Prostate cancer involving the bladder neck: recurrence-free survival and implications for AJCC staging modification: American Joint Committee on Cancer. Urology 2002;60:276-280.

59 Billis A, Freitas L, Magna L, et al. Prostate cancer with bladder neck involvement: pathologic findings with application of a new practical method for tumor extent evaluation and recurrence-free survival after radical prostatectomy. Int Urol Nephrol 2004;36: 363-368.

60 Poulos C, Koch M, Eble J, et al. Bladder neck invasion is an independent predictor of prostate specific antigen recurrence. Cancer 2004;101:1563-1568.

61 Zhou M, Reuther A, Levin H, et al. Microscopic bladder neck involvement by prostate carcinoma in radical prostatectomy specimens is not a significant independent prognostic factor. Mod Pathol 2009;22: 385-392.

62 Ploussard G, Rotondo S, Salomon L. The prognostic significance of bladder neck invasion in prostate cancer: is microscopic involvement truly T4 disease? BJU Int 2009;105:776-781.

63 Osunkoya A, Grignon D. Practical issues and pitfalls in staging tumors of the genitourinary tract. Sem Diagn Pathol 2012;29:154-166.

64 Tefilli M, Gheiler E, Tiguert R, et al. Prognostic indicators in patients with seminal vesicle involvement following radical prostatectomy for clinically localized prostate cancer. J Urol 1998;160:802-806.

65 Epstein J, Partin A, Potter S, et al. Adenocarcinoma of the prostate invading seminal vesicle: prognostic stratification based on pathologic parameters. Urology 2000;56:283-288.

66 Ohori M, Scardino P, Lapin S, et al. The mechanisms and prognostic significance of seminal vesicle involvement by prostate cancer. Am J Surg Pathol 1993;17: 1252-1261.

67 Emerson R, Koch M, Daggy J, et al. Closest distance between tumor and resection margin in radical prostatectomy specimens: lack of prognostic significance. Am J Surg Pathol 2005;29:225-229.

68 Epstein J, Sauvageot J. Do close but negative margins in radical prostatectomy specimens increase the risk of postoperative progression? J Urol 1997;157: 241-243.

69 Sammon J, Trinh Q-D, Sukumar S, et al. Risk factors for biochemical recurrence following radical perineal prostatectomy in a large contemporary series. A detailed assessment of margin extent and location. Urol Oncol 2013;31:1470-1476.

70 Sofer M, Hamilton-Nelson K, Civantos F, et al. Positive surgical margins after radical prostatectomy: then influence of site and number on progression. J Urol 2002;167:2453-2456.
71 Pettus J, Weight C, Thompson C, et al. Biochemical failure in men following radical retropubic prostatectomy: impact of surgical margin status and location. J Urol 2004;172:129-132.

72 Eastham J, Kuroiwa K, Ohori M, et al. Prognostic significance of location of positive margins in radical prostatectomy specimens. Urology 2007;70: 965-969.

73 Saether T, Sorlien L, Viset T, et al. Are positive surgical margins in radical prostatectomy specimens an independent prognostic marker? Scand J Urol Nephrol 2008;42:514-521.

74 Sooriakumaran P, Ploumidis A, Nyberg T, et al. The impact of length and location of positive margins in predicting biochemical recurrence after robot-assisted radical prostatectomy with minimum follow-up of 5 years. BJU Int 2015;115:106-113.

75 Fleshner N, Evans A, Chadwick K, et al. Clinical significance of the positive surgical margin based upon location, grade, and stage. Urol Oncol 2010;28: 197-204.

76 Kozal S, Peyronnet B, Cattarino S, et al. Influence of pathological factors on oncological outcomes after robot-assisted radical prostatectomy for localized prostate cancer: results of a prospective study. Urol Oncol 2015;33:330e331-330e337.

77 Cao D, Humphrey P, Gao F, et al. Ability of length of positive margin in radical prostatectomy specimens to predict biochemical recurrence. Urology 2011;77: 1409-1414.

78 Chuang A, Nielsen M, Hernandez D, et al. The significance of positive surgical margin in areas of capsular incision in otherwise organ confined disease at radical prostatectomy. J Urol 2007;178:1306-1310.

79 Savdie R, Horvath L, Benito R, et al. High Gleason grade carcinoma at a positive surgical margin predicts biochemical failure after radical prostatectomy and may guide adjuvant therapy. BJU Int 2012;109: 1794-1800.

80 Babaian R, Troncoso P, Bhadkamkar V, et al. Analysis of clinicopathologic factors predicting outcome after radical prostatectomy. Cancer 2001;91:1414-1422.

81 Alkhateeb S, Alibhai S, Fleshner N, et al. Impact of positive surgical margins after radical prostatectomy differs by disease group. J Urol 2010;183:145-150.

82 Brimo F, Partin A, Epstein J. Tumor grade at margins of resection in radical prostatectomy specimens is an independent predictor of prognosis. Urology 2010;76: 1206-1209.

83 Ohori M, Wheeler T, Kattan M, et al. Prognostic significance of positive surgical margins in radical prostatectomy specimens. J Urol 1995;154:1818-1824.

84 Gupta R, O'Connell R, Haynes A-M, et al. Extraprostatic extension (EPE) of prostatic carcinoma: is its proximity to the surgical margin or Gleason score important? BJU Int 2015;116:343-350.

85 Shuford M, Cookson M, Chang S, et al. Adverse prognostic significance of capsular incision with radical retropubic prostatectomy. J Urol 2004;172: 119-123.

86 Preston M, Carriere M, Raju G, et al. The prognostic significance of capsular incision into tumor during radical prostatectomy. Eur Urol 2011;59:613-618.

87 Cao D, Kibel A, Gao F, et al. The Gleason score of tumor at the margin in radical prostatectomy is predictive of biochemical recurrence. Am J Surg Pathol 2010;34:994-1001. 
88 Cheng L, Jones TD, Lin $\mathrm{H}$, et al. Lymphovascular invasion is an independent prognostic factor in prostatic adenocarcinoma. J Urol 2005;174: 2181-2185.

89 van den Ouden D, Kranse R, Hop W, et al. Microvascular invasion in prostate cancer: prognostic significance in patients treated by radical prostatectomy for clinically localized carcinoma. Urol Int 1998;60:17-24.

90 Kang M, Oh J, Lee S, et al. Perineural invasion and lymphovascular invasion are associated with increased risk of biochemical recurrence in patients undergoing radical prostatectomy. Ann Surg Oncol 2016;23:2699-2706.

91 Galiabovitch E, Hovens C, Peters J, et al. Routinely reported "equivocal" lymphovascular invasion in prostatectomy specimens is associated with adverse outcomes. BJU Int 2017;119:567-572.

92 Park Y, Kim Y, Choi I, et al. Is lymphovascular invasion a powerful predictor for biochemical recurrence in pT3 No prostate cancer? Results from the K-CaP database. Sci Rep 2016;6:25419.

93 Kang Y, Kim H-S, Jang W, et al. Impact of lymphovascular invasion on lymph node metastasis for patients undergoing radical prostatectomy with negative resection margin. BMC Cancer 2017;17:321.

94 Fajkovic H, Mathieu R, Lucca I, et al. Validation of lymphovascular invasion as an independent prognostic factor for biochemical recurrence after radical prostatectomy. Urol Oncol 2016;34: 233e231-233e236.

95 Kryvenko O, Epstein J. Histologic criteria and pitfalls in the diagnosis of lymphovascular invasion in radical prostatectomy specimens. Am J Surg Pathol 2012;36:1865-1873.

96 Passoni N, Fajkovic H, Xylinas E, et al. Prognosis of patients with pelvic lymph node (LN) metastasis after radical prostatectomy: value of extranodal extension and size of largest LN metastasis. BJU Int 2014;114: 503-510.

97 Sgrignoli A, Walsh P, Steinberg G, et al. Prognostic factors in men with stage D1 prostate cancer: identification of patients less likely to have prolonged survival after radical prostatectomy. J Urol 1994;152: 1077-1081.

98 Cheng L, Bergstralh E, Cheville J, et al. Cancer volume of lymph node metastasis predicts progression in prostate cancer. Am J Surg Pathol 1998;22:1491-1500.

99 Boormans J, Wildhagen M, Bangma C, et al. Histopathological characteristics of lymph node metastases predict cancer-specific survival in node-positive prostate cancer. BJU Int 2008;102:1589-1593.

100 Luchini C, Fleischmann A, Boormans J, et al. Extranodal extension of lymph node metastasis influences recurrence in prostatic cancer: a systematic review and meta-analysis. Sci Rep 2017;7:2374. 